J-DEPACE, Volume 2, Nomor 1, Juni 2019, Hal. 95 - 102

Tersedia online di:http://jurnal.lpmiunvic.ac.id/index.php/jpkm

\title{
PELATIHAN KEPEMIMPINAN BAGI SISWA SMA NEGERI 2 KABUPATEN SORONG
}

\author{
Adolfina Putnarubun, Susana M.W. Muskita, Ratna R. Pakpahan, \\ Arce Y. Ferdinandus, Junnet Wattimena \\ Universitas Victory Sorong \\ email: adolfinaputnarubun87@gmail.com
}

\begin{abstract}
ABSTRAK
Seiring perkembangan zaman, kepemimpinan secara ilmiah mulai berkembang bersamaan dengan pertumbuhan manajemen ilmiah yang lebih dikenal dengan ilmu tentang memimpin. Hal ini terlihat dari banyaknya literatur yang mengkaji tentang kepemimpinan dengan berbagai sudut pandang atau perspektifnya. Kepemimpinan tidak hanya dilihat dari baik saja, akan tetapi dapat dilihat dari penyiapan sesuatu secara berencana dan dapat melatih caloncalon pemimpin. Para siswa sebagai calon pemimpin masa depan bangsa dan Negara sudah tentu harus mendapatkan perhatian khusus dari kita sebagai pendidik. Dalam hal ini, para siswa sejak dini mungkin dibekali dengan berbagai macam teori dan keterampilan tentang mempin, sehingga para siswa dapat menjadi pemimpin bagi dirinya sendiri maupun pemimpin dalam sebuah kelompok dan organisasi. Seorang pemimpin harus memiliki syaratsyarat yang tidak ringan, karena pemimpin sebagai ujung tombak kelompok. PKM yang kami lakukan berdasarkan munculnya banyak persoalan dikalangan Pelajar yang dapat menarik perhatian Pelajar, sehingga merusak masa depan mereka. Metode yang kami gunakan dalam PKM ini adalah kualitatif deskriptif, dimana hasil PKM ini kedumudian akan dideskripsikan. Dari PKM yang kami lakukan, dapat ditemukan bahwa adanya peningkatan pemahaman dari para Pelajar tentang bagaimana mempersiapkan diri menjadi seorang pemimpin yang baik.
\end{abstract}

Kata Kunci: Pelatihan, Kepemimpinan, Pelajar

\section{ABSTRACT}

Along with the development of the times, scientific leadership began to develop along with the growth of scientific management, better known as the science of leadership. Can be seen from the many kinds of literature that examine leadership with various perspectives or perspectives. Leadership is not only seen from the good but can be seen from the preparation of something in a plan and can train prospective leaders. The students as candidates for future leaders of the nation and the State certainly need to get special attention from us as educators. In this case, early students may be equipped with a variety of theories and skills about education, so that students can become leaders for themselves and leaders in a group and organisation. A leader must have conditions that are not light because the leader is the spearhead of the group. PKM that we do base on the emergence of many problems among students who can attract the attention of students, thus damaging their future. The method we use in this PKM is descriptive qualitative, where the results of this PKM will later describe. 
From the PKM that we did, it found that there was an increase in the understanding of the students about how to prepare to be a good leader.

Keywords: Training, Leadership, Students

\section{PENDAHULUAN}

Terwujudnya sebuah tujuan dalam sebuah organisasi atau sekelompok masyarakat maupun skop terkecil adalah tujuan diri sendiri tidak terlepas dari siapa pemimpinnya atau bagaimana cara seseorang dalam memimpin. Banyak definisi tentang pemimpin yang dapat kita ketahui, namun dalam hal ini dapat dipahami bahwa Pemimpin adalah seseorang yang mampu menggerakkan orang lain untuk bekerjasama dalam muwujudkan tujuan bersama.

Pemimpin yang baik adalah seseorang yang telah dibekali secara dini tentang bagaimana memiliki jiwa seorang pemimpin atau dalam hal ini pribadi yang senantiasa dibina untuk mampu memimpin orang lain dimulai dari kemampuannya memimpin dirinya sendiri.

Kepemimpinan adalah sesuatu yang sangat dibutuhkan dimanapun kita berada, di sekolah, rumah dan tempat umum lainya. Setiap perkumpulan harus ada seseorang yang memimpin perkumpulan tersebut, contoh paling sederhana adalah saat di sekolah dan di dalam kelas ada siswa yang menjadi ketua kelas, dia-lah yang disebut pemimpin. Oleh karena itu pengenalan kepemimpinan saat ini sangat dibutuhkan bagi para pelajar.

Pelajar merupakan calon pemimpin masa depan sehingga sudah seharusnya dibina serta dibekali terus-menerus dalam bangku pendidikan agar dapat menjadi pemimpin yang berintegritas nantinya. Minimnya kesadaran pelajar tentang jiwa pemimpin yang ada dalam dirinya dapat berdampak pada pencapaian cita-cita pribadi maupun bangsa ini. Menurut UU SISDIKNAS No.20 tahun 2003, Pendidikan adalah usaha sadar dan terencana untuk mewujudkan suasana belajar dan proses pembelajaran agar peserta didik aktif mengembangkan potensinya untuk memiliki kekuatan spiritual keagamaan, pengendalian diri, kepribadian, kecerdasan, akhlak mulia serta keterampilan yang diperlukan dirinya dan masyarakat.

Untuk itu, kelangsungan dan kesejahteraan Bangsa dan Negara tergantung pada babagaimana tanggungjawab kita sebagai generasi Tua, mempersiapkan generasi Muda dengan berbagai ilmu agar kelak dapat menjadi pemimpin yang mempimpin dengan bijak. 
Demi terwujudnya generasi bangsa yang berjiwa pemimpin maka, pelaksanaan pengabdian kepada masyarakat dalam bentuk Sosialisasi sebagai penerapan praktis dalam memberikan wawasan yang baik kepada generasi muda. Konteks masa kini dimana cerminan tokoh pemimpin pada masa kini sebagian besar kurang memiliki jiwa kepemimpinan, sehingga dalam menjalankan tugas dan tanggungjawabnya masih terdapat banyak kepincangan. Inilah yang menjadi acuan dalam terwujudnya sebuah tekad untuk secara bersama memberi pemahaman yang benar kepada para pelajar dalam mempersiapkan diri mereka sejak dini, sehingga kelak menjadi pemimpin yang baik.

Pemimpin yang baik akan lahir dari pelajar yang baik pula, untuk itu sebagai pengajar kami sebagai Tim Dosen mengambil langkah untuk melakukan PKM dalam Wujud Pelatihan Kepemimpinan kepada SIswa/I SMA Negeri 2 Kabupaten Sorong. Pelatihan Kepemimpinan yang kami lakukan merupakan tindakan nyata dari sebuah kegelisahan terhadap dinamika pergaulan Pelajar yang semakin hari semakin memprihatinkan. Pelajar terlibat dalam kenakalan pelajar dan pergaulan bebas, sehingga dapat merusak masa depan mereka. Tujuan yang ingin dicapai adalah agar Siswa/i dapat memiliki motivasi yang kuat dan percaya diri untuk memimpin diri sendiri, sehingga dapat mampu menerima tanggungjawab kepemimpinan dalam sebuah organisasi yang lebih besar lagi kedepan.

\section{MASALAH}

Tujuan pendidikan adalah mendidik peserta didik untuk menemukan potensi dalam dirinya serta menjadi pribadi yang memiliki moral yang baik, segingga sebagai generasi penerus bangsa, para pelajar dapat memiliki jiwa kepemimpinan sejak dini. Untuk mendukung tujuan tersebut maka dibutuhkan sebuah pelatihan yang berjenjang. Maka PKM merupakan salah satu wujud tanda bukti kepedulian kami sebagai tenaga pendidik dalam mempersipakan generasi yang berjiwa kepemimpinan. Namun dalam kenyataannya masih banyak pelajar yang mengalami kendala dalam memahami dirinya sendiri, khususnya dalam kepemimpinan. Berdasar latar belakang tersebut maka identifikasi masalah yang diajukan adalah:

a. Terdapat banyak kendala yang mempengaruhi para Pelajar dalam memahami potensi yang ada di dalam dirinya. 
b. Masih banyak Pelajar yang mengalami kesulitan dalam menempatkan diri sebagai pemimpin bagi dirinya sendiri.

c. Terdapat beberapa Pelajar yang tidak mampu mengelola potensi dalam dirinya, sehingga sering merasa tidak mampu/rendah diri.

Berdasarkan permasalahn diatas maka, dapat rumusan dari masalah ini adalah : Bagaimana cara menjadi Pemimpin yang baik?

\section{METODE}

Untuk memecahkan masalah yang sudah diidentifikasi dan dirumuskan tersebut di atas, agar pelatihan dapat berjalan dengan lancar maka sebagai alternatif pemecahan masalah adalah sebagai berikut: pendampingan dilakukan dengan pendekatan individual dan klasikal. Pendekatan klasikal dilakukan pada saat pemberian teori tentang Siap Menjadi Pemimpin dan pendekatan individual dilakukan pada saat latihan teknik kepemimpinan. Adapun metode yang digunakan adalah:

\subsection{Metode Pelaksanaan}

a. Ceramah bervariasi.

Metode ini dipilih untuk menyampaikan konsep-konsep yang penting untuk dimengerti dan dikuasai oleh peserta pelatihan. Penggunaan metode ini dengan pertimbangan bahwa metode ceramah yang dikombinasikan dengan gambargambar, animasi dan display dapat memberikan materi yang relatif banyak secara padat, cepat dan mudah. Materi yang diberikan meliputi: Konsep Kepemimpinan, Jenis-jenis Organisasi Intra dan Ekstra Sekolah, Syarat Kepemimpinan, Sikap seorang Pemimpin, dan langkah-langkah menjadi seorang Pemimpin.

\section{b. Demonstrasi}

Metode ini dipilih untuk menunjukkan suatu proses kerja yaitu Sikap Seorang Pemimpin. Demonstrasi dilakukan oleh instruktur di hadapan peserta yang telah dikelompokan dan menunjuk salah seorang menjadi pemimpin kelompok.

c. Latihan

Metode ini digunakan untuk memberikan tugas kepada peserta pendampingan untuk mempraktikkan Cara memimpin sebuah kelompok. 


\subsection{Teknik Pelaksanaan}

Adapun Teknik Pelaksanaan kegiatan yang dilakukan adalah pendampingan secara intensif dengan tahapan sebagai berikut:

a. Ceramah tentang Apa itu Pemimpin dan Kepemimpinan

b. Ceramah tentang teori Kepemimpinan

c. Ceramah tentang pengembangan Jenis-jenis Organisasi Intra dan Ekstra Sekolah

d. Demonstrasi tentang langkah-langkah menjadi seorang Pemimpin

e. Latihan Memimpin kelompok dengan benar

f. Evaluasi tingkat pemahaman tentang Kepemimpinan.

\section{Ceramah}
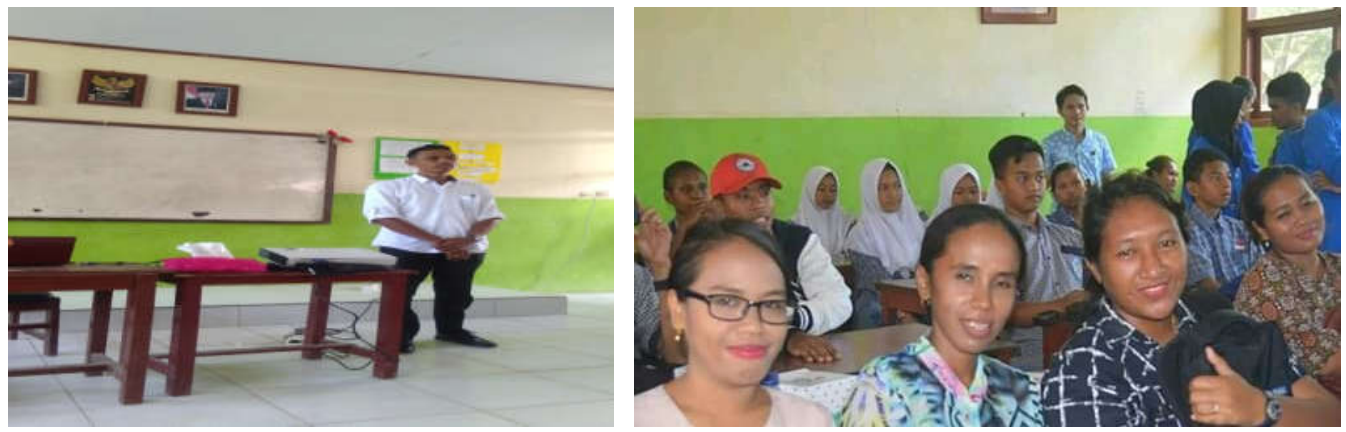

Gambar 1. Penyampaian Materi Kepemimpinan

\section{Demontrasi Pemimpin}
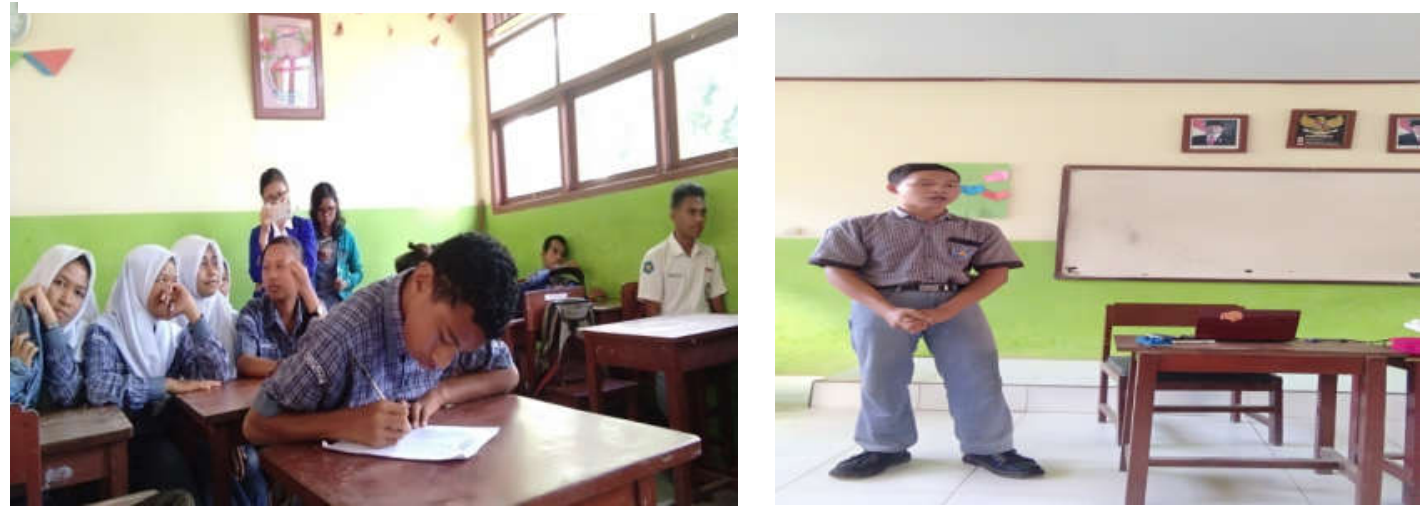

Gambar 2. Demonstrasi Materi Kepemimpinan 


\section{Latihan Memimpin}
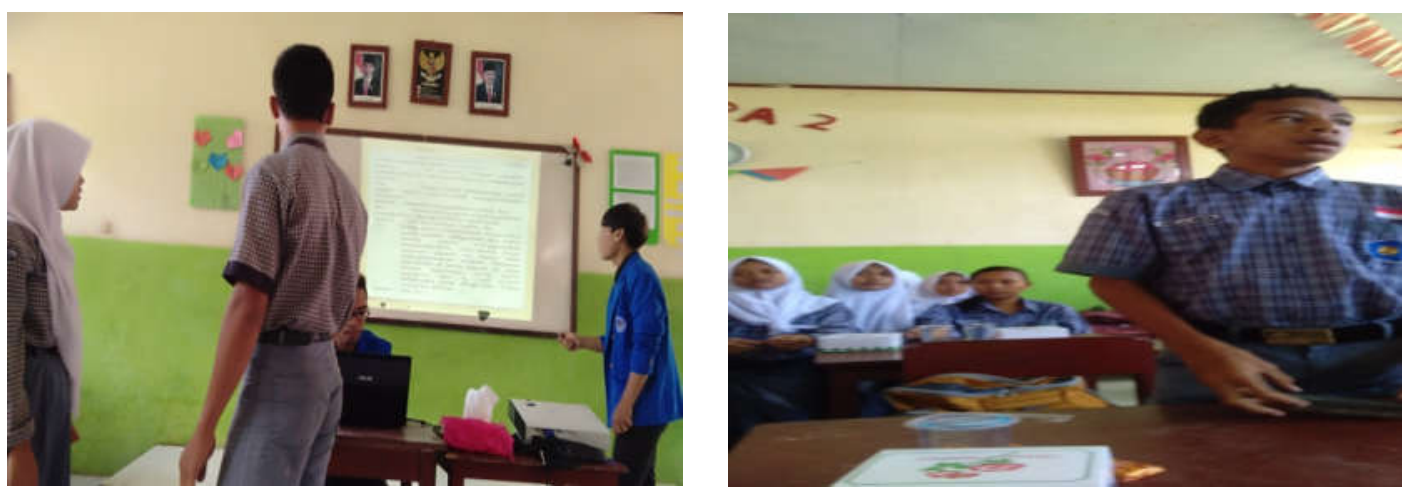

Gambar 3. Latihan Kepemimpinan

\subsection{Lokasi, Waktu dan Durasi Kegiatan}

Lokasi : Kegiatan Pelatihan Kepemimpinan Belangsung di SMA Negeri 2 Kabupaten Sorong

Waktu : Waktu pelaksanaan kegiatan pada hari Rabu, tanggal 18 bulan April Tahun 2018

Durasi Kegiatan : Kegiatan berlangsung dari Pukul 10:00 WIT sampai dengan Pukul 14:30 WIT.

\section{PEMBAHASAN}

Pelaksana dan Peserta Pengabdian dalam bentuk Pelatihan: Kepemimpinan dengan Tema "Peduli Anak Bangsa" dikalangan Pelajar dilaksanakan oleh Tim Dosen. Jumlah anak-anak yang mengikuti kegiatan ini sebanyak 39 Siswa. Anak-anak diberikan pemahaman tentang kepemimpinan.

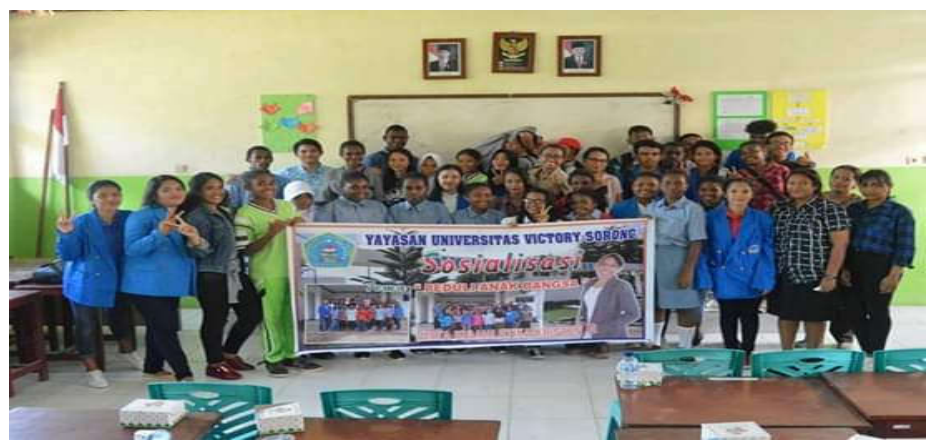

Gambar 4. Penyampaian Materi Kepemimpinan Pada SMA Negeri 2 Kab. Sorong 
Hasil dari Kegiatan Sosialisasi ini adalah Siswa/i di SMA Negeri 2 Kabupaten Sorong dengan serangkaian kegiatan diantaranya ceramah dan pelatihan dengan materi yang diberikan meliputi: Konsep Kepemimpinan, Jenis-jenis Organisasi Intra dan Ekstra Sekolah, Syarat Kepemimpinan, Sikap seorang Pemimpin, dan langkahlangkah menjadi seorang Pemimpin serta Denmostrasi tentang cara memimpin dengan baik. Dengan demikian maka para pelajar mulai memahami apa itu pemimpin, kepemimpinan, langkah-langkah menjadi pemimpin serta tujuan seorang pemimpin dalam memimpin sebuah kelompok. Adapula sebagian Pelajar yang mulai termotivasi serta percaya diri untuk siap menjadi pemimpin. Hal ini dapat dilihat dari antusias para siswa dalam mempraktekkan cara memimpin yang baik dan memberikan tanggapan secara langsung.

\section{- Keunggulan dan Kelemahan}

\section{Keunggulan :}

1. Adanya kerjasama Tim dari Mahasiswa/i, Rekan Dosen Fakultas dan Pihak Sekolah

2. Antusias Siswa-siswi di SMA Negeri 2 Kabupaten Sorong untuk mengikuti kegiatan ini

3. Dengan adanya Sosialisasi ini, para siswa lebih memahami dirinya dan memiliki konsep diri yang benar dalam meraih masa depannya.

\section{Kelemahan :}

Dari segi durasi waktu yang terbatas, membuat keterbatasan pula dalam sesi diskusi bersama para siswa.

\section{- Tingkat Kesulitan}

Tidak ada, hal ini dapat dilihat dari proses jalannya kegiatan dari awal sampai berakhir sesuai dengan apa yang telah direncanakan.

\section{KESIMPULAN}

Kesadaran akan pentingnya memimpin harus disampaikan kepada generasi muda sejak dini, sehingga dalam meniti masa depannya seorang remaja sudah memiliki kepercayaan diri yang utuh untuk siap menjadi pemimpin yang baik. Ketercapaian dalam proses Pelatihan Kepemimpinan ini dilihat dari meningkatnya kepercayaan diri dari para siswa dan juga memiliki pemahaman yang lebih lagi tentang kepemimpinan. 


\section{DAFTAR PUSTAKA}

Ardana, Komang, dkk. (2008). Perilaku Keorganisasian. Yogyakarta: Graha Ilmu Chaniago, Nasrul Syakur, (2011).Manajemen Organisasi, Bandung, Cita Pustaka Pudjo Sumedi, (2010). Organisasi dan Kepemimpinan, Jakarta, Uhamka Press Rivai, Veithzal, (2007). Kepemimpinan dan Perilaku Organisasi, Jakarta: PT.Raja Grafindo Persada 